Original article

\title{
The correlation between low back pain and disability index with lumbar lordosis among dentists
}

\author{
Fatemeh Fasih-Ramandi ${ }^{1}$, Amir Nadri ${ }^{2}$, Gholamheidar Teimori ${ }^{3}$, Hamed Nadri ${ }^{4}$ \\ ${ }^{1}$ Shahid Beheshti University of Medical Sciences, Tehran, Iran \\ ${ }^{2}$ Izeh Islamic Azad University, Khozestan, Iran \\ ${ }^{3}$ Torbat Heydariyeh University of Medical Sciences, Torbat Heydariyeh, Iran \\ ${ }^{4}$ Tarbiat Modares University, Tehran, Iran
}

Received 05 June 2018, Revised 22 October 2018, Accepted 21 January 2019

(C) 2018, Fasih-Ramandi F., Nadri A., Teimori G., Nadri H.

(C) 2018, Russian Open Medical Journal

Abstract: Background - Non-specific low back pain (LBP) has direct impact on life quality, active days at work and health care costs. The aim of this study was to examine the correlation between lumbar lordosis (LL), LBP intensity and low back pain disability index (LBPDI). Material and Methods - This cross-sectional study was conducted among 52 dentists ( $56 \%$ male and $44 \%$ female). Dentists' low back pain intensity and low back disability index were examined with the self-administered visual analog scale and modified Oswestry questionnaire, respectively. LL was calculated using flexible ruler based on Youda's method.

Results - The mean LBP and LBPDI were equal to $61.0 \pm 23.7$ and $31.4 \pm 11.8$, respectively. In addition, a significant relationship between $L B P$, sex and $B M I$ as well as between $L B P D I$, work experience and $B M I$ were found $(P=0.001)$. There was a strong significant positive correlation between LBP and LBPDI ( $P=0.001, r=0.937)$. Additionally, the results showed no significant correlation between LBP, $L B P D I$ and $\mathrm{LL}(\mathrm{P}>0.05)$.

Conclusion - The results suggest that despite the lack of correlation between LBP intensity and LBPDI with LL, male sex, work experience and BMI are the important risk factors associated with LBP and LBPDI in dentists and thus should be taken into consideration for preventative and intervention strategies.

Keywords: disability index, low back pain, lumbar lordosis.

Cite as Fasih-Ramandi F, Nadri A, Teimori G, Nadri H. The correlation between low back pain and disability index with lumbar lordosis among dentists. Russian Open Medical Journal 2019; 8: e0207.

Correspondence to Hamed Nadri. E-mail: nadri.hamed@yahoo.com. Phone: 009821-82883849.

\section{Introduction}

Efficient and safe interaction between people, environment and equipment is a concern of ergonomics, an applied science [1]. Workrelated musculoskeletal disorders have been reported as the most important reason for early retirement among dentists, among which the lower back pain (LBP) is the most prevalent $[2,3]$. The main reason for undesirable and non-ergonomic positions among dentists is with the aim of achieving an ideal view of the patient's mouth and providing a comfortable position for the patient $[1,4]$.

LBP is a multifactorial disorder, the most common risk factors of which include abnormal postures such as static postures during work) plus lack of flexibility and weakness of abdominal and gluteal muscles which serve as the stabilizers of the lumbar spine and lumbar lordosis (LL) [1].

Significant correlation has been reported between LL and LBP [5], documented by the fact that the therapeutic exercise recommended by clinicians to abolish LL can be applied in order to relieve and treat LBP, and therefore it is believed that LLplays a shock-absorbing role in the prevention of LBP [6].

LBP can lead to disability of the spine and has adverse effects on daily work, personal activities and quality of life, so it is essential that researchers use tools having acceptable validity and reliability to review the disability level of LBP and to determine its consequences $[7,8]$.

Measuring disability is an important component in the management of patients with LBP. Self-report questionnaire of Oswestry Disability Index (ODI) is one of the most strong available tool which reports the average value of symptom during last week, which is named low back pain disability index (LBPDI), and is confirmed by the American Academy of Orthopedic Surgeons (AAOS). It measures permanent functional inability with emphasizing on physical activities and not the psychological consequences of the pain [9]. Along with the assessment of LBP, disability measurement is important in management of preventive actions. The aim of this study was to investigate the correlations between lumbar lordotic angle, LBP, and LBPDI among dentists.

\section{Material and Methods}

\section{Subjects}

This cross-sectional study was conducted in a dental specialized clinic in Tehran, Iran in the year 2017. In this study, 52 dentists with LBP were selected after completion of body map questionnaire. The 
criteria for inclusion in the study were the lack of a history of spinal surgery and traumatic orthopedic problems such as acute back and nerve problems, inflammatory diseases such as Ankylosing spondylitis involving the spine, congenital diseases such as scoliosis and hemi vertebrae. Due to the inclusion criteria, 2 dentists were excluded from the study. LBP intensity and disability indices were evaluated by a visual analogue discomfort scale and Oswestry questionnaire. LL was measured using flexible ruler based on Youda's method [10]. All participants agreed to participate in this study, read and signed an informed consent form approved by the ethics committee of Shahid Beheshti University of Medical sciences. Furthermore, we measured body mass index (BMI), which according to the health communities [11] is a measure of body fat calculated by person's weight in kilograms divided by the square of height in meters.

\section{Visual analogue discomfort scale}

To indicate the level of discomfort the subjects were asked to mark degree of subjective discomfort on a horizontal line of $100 \mathrm{~mm}$ long. Subjective intensity of discomfort was recorded numerically from zero (without discomfort) to 100 (severe discomfort) using a millimetre ruler. The advantages of this tool include its ease of management, sensitivity and amenability to statistical analysis [12].

\section{Oswestry disability index}

A modified version of the Oswestry's disability index selfadministered questionnaire with 10 items was used to examine the degree of physical disability resulted from chronic LBP and its effect on the daily activities of the person. In each section, the degree of physical disability was scored from zero (desirable performance and without pain) to five (disability in performance due to severe pain). Finally, the physical disability degree was classified as mild ( 0 to $20 \%$ ), moderate ( 21 to $40 \%$ ), severe (41 to $60 \%$ ), disabling (61 to $80 \%$ ) and severely disabling (81 to $100 \%$ ) [9].

\section{Lumbar lordosis measurement}

LL was measured using flexible ruler (Ghamat Pooyan Co., Iran) based on Youda's method $[10,13,14]$. We used a flexible ruler for the measurement of $\mathrm{LL}$, according to the distance of the spinous process of two reference bones, i.e. T12 and S2. The Hoppenfeld method was employed to find the two bone landmarks [15]. Finally, the angle between these two bone landmarks (T12 and S2) was calculated and reported as LL.

\section{Statistical analysis}

Statistical data analysis was done using SPSS (version 22.0, IBM Corporation, Armonk, NY, USA). Kolmogorov-Smirnov test was used to determine the normality of the data. Independent samples test was used to evaluate the mean differences of LBP, LBPDI and LL between marital status and sex groups, while the Pearson and Spearman correlation coefficients were employed to test the correlation between LBP, LBPDI and LL with age, work experience and body mass index (BMI). Correlation of $\mathrm{BMI}$, sex, age and work experience variables with the LBP, LBPDI and LL was analysed using linear regression models. The confidence level was considered as $\mathrm{P}$-value $\leq 0.05$.
Table 1. Distribution of dentist's demographic characteristics

\begin{tabular}{lcc}
\hline Variables & Mean $\pm S D$ & Range \\
\hline Age, years & $36.2 \pm 5.1$ & $29-48$ \\
Experience, years & $10.4 \pm 5.3$ & $2-20$ \\
Height, cm & $172.3 \pm 9.4$ & $157-190$ \\
Weight, kg & $79.5 \pm 13.3$ & $42-120$ \\
BMI, kg/m & $26.6 \pm 2.6$ & $21.1-35.1$ \\
\hline
\end{tabular}

SD, standard deviation.

\section{Results}

The characteristics of the participants are highlighted in Table 1. Fifty-six and 44 percent of the subjects were female and male, respectively; also 34 and 66 percent of the participants were single and married, respectively. In this study, 30, 58 and 12 percent of the participants were classified in the normal, overweight and obese classes. Therefore, the highest frequency of body mass index of people belonged to the normal class.

The mean disability caused by LBP and LBPDI were equal to $61 \pm 23.7$ and $31.4 \pm 11.8$, respectively; LBP and LBPDI in 32 and 42 percent of participants were classified as disabling and moderate classes, respectively. In addition, there was a strong significant positive correlation between LBP and LBPDI. Distribution of LBP and LBPDI among the dentists is presented in Table 2.

The correlation between LBP, LBPDI and LL with dentist's characteristics are shown in Table 3. A significant relationship was reported between LBP, sex and BMI; and also between LBPDI, work experience and BMI. There was a significant relationship between lumbar curvature angle and sex, marriage status and age .

The results of the linear regression analyses for LBP, LBPDI and LL are reported in Table 4. Among the total participants, being male and increase of BMI were significant risk factors for LBP, while in the case of LBPDI, work experience and BMI were reported as significant risk factors. As shown by the linear regression equation, female sex and increase of age led to an augmentation of the $L L$ (Adjusted $R^{2}=0.997$; $\mathrm{P}=0.001)$. Furthermore, male sex and increase of $\mathrm{BMl}$ resulted in an increase of the LBP (Adjusted $R^{2}=0.462 ; P=0.001$ ). Concordantly, increase of work experience and $\mathrm{BMI}$ caused an increase of the LBPDI (Adjusted $R^{2}=0.377 ; P=0.001$ ). At the end, the results showed no significant correlation between LBP, LBPDI and LL ( $P>0.05)$.

\section{Discussion}

The aim of this study was to test the hypotheses that LBP intensity and LBPDI are related to LL in dentists. We reported no significant correlation between LL in dentists with LBP and LBPDI. Our findings are aligned with the results of Evcik and Yucel [16] that reported no statistical correlation between LL and chronic LBP patients. In addition, a systematic review and meta-analysis by Laird et al. [17] showed no significant difference of lumbar lordotic curvature between subjects with and those without LBP. On the other hand, Christopher et al. reported a significant positive relationship between LBP intensity and the degree of lordosis [5]; also in a systematic review and metaanalysis consisting of 13 studies including 796 and 927 patients with and without LBP respectively Chun et al. [6] reported that patients with LBP have smaller lumbar lordotic angle rather than patients without LBP. Although in our study a significant differences in age, gender, marital status and lumbar lordotic angle were observed, linear regression equation showed that just female sex and increase of age could lead to an increase of the LL. Therefore, our findings are aligned with the results of Evcik and Yucel [16] that showed females had greater lumbosacral angle. 
Table 2. Percent distribution of LBP and LBPDI among dentists

\begin{tabular}{|c|c|c|c|c|c|c|c|c|}
\hline \multirow{2}{*}{ Variable } & \multirow{2}{*}{$\operatorname{Mean}(S D)$} & \multicolumn{5}{|c|}{ Physical disability (\%) } & \multirow{2}{*}{ P-value* } & \multirow{2}{*}{$r$} \\
\hline & & Mild & Moderate & Severe & disabling & Severe disabling & & \\
\hline LBP & $61.0 \pm 23.7$ & 2 & 26 & 16 & 32 & 24 & 0.001 & 0.937 \\
\hline
\end{tabular}

Data are presented as mean with standard deviation $-\mathrm{M} \pm \mathrm{SD}$, and frequency with percentage $-\mathrm{n}(\%)$. ${ }^{*}$ Pearson correlation test (between LBP and LBPDI).

Table 3. Relationship between LBP, LBPDI and LL with dentist's characteristics

\begin{tabular}{|c|c|c|c|c|c|c|c|c|}
\hline \multirow{2}{*}{ Variable } & \multirow{2}{*}{$\begin{array}{c}\text { Sex } \\
\text { P-value* }\end{array}$} & \multirow{2}{*}{$\begin{array}{l}\text { Married } \\
\text { P-value }\end{array}$} & \multicolumn{2}{|c|}{ Age } & \multicolumn{2}{|c|}{ Experience } & \multicolumn{2}{|c|}{$B M I$} \\
\hline & & & P-value & $r^{* *}$ & P-value & $r^{* *}$ & P-value** & $r^{* *}$ \\
\hline LBP & 0.005 & 0.623 & 0.335 & 0.13 & 0.118 & 0.22 & 0.001 & 0.70 \\
\hline LBPDI & 0.085 & 0.885 & 0.128 & 0.21 & 0.025 & 0.31 & 0.001 & 0.59 \\
\hline LL & 0.003 & 0.001 & 0.001 & 0.76 & 0.001 & 0.70 & 0.472 & -0.10 \\
\hline
\end{tabular}

* Independent samples test; ** Pearson or Spearman correlation coefficients.

Table 4. Linear regression models for correlates of LBP, LBPDI and LL

\begin{tabular}{|c|c|c|c|}
\hline Variable & Adjusted $R^{2}$ & $P$-value* & Linear regression equation \\
\hline LBP with Sex \& BMI & 0.462 & 0.001 & $\mathrm{LBP}=-57.022-(12.830 \times \mathrm{Sex})+(5.125 \times \mathrm{BMI})$ \\
\hline LBPDI with Experience \& BMI & 0.377 & 0.001 & LBPDI=-39.033+(0.523 $\times$ Experience $)+(2.439 \times \mathrm{BMI})$ \\
\hline LL with Sex and Age & 0.997 & 0.001 & $L L=-14.689+(8.697 \times$ Sex $)+(1.323 \times$ Age $)$ \\
\hline
\end{tabular}

* Multiple linear regression model.

In a previous study, we reported that $60 \%$ of dentists had moderate LBPDI [18], similar to the data by Ilyas and Dharmaji [19] who reported $74.4 \%$ and $25.6 \%$ of mild to moderate LBPDI among the subjects. While here we observed only $32 \%$ of disabling pain, however, it should be noted that although in subjects with moderate LBPDI, personal care and sleep are not affected greatly, they work experience more pain while sitting, standing and lifting, and thus traveling and social life become difficult for them which could possibly lead to missing work.

Here, a significant positive relationship was obreved between LBP, sex and BMI and similarly between LBPDI, work experience and BMI. This was especially evident in the case of BMI. Our finding are aligned with the results of our previous study [18] and Youdas et al. [20] studies, that reported higher risk of LBP in women and men with a higher BMI.

The high prevalence of LBP among dentists related to the posture and movements in their daily work have been reported in the previous studies [2, 18, 21]. In a sitting position, lumbar lordotic curvature drops and prevents LBP. Also during standing position, $40-70 \%$ of back-healthy people reported LBP symptoms [22]. Therefore change of the working positions and thus involving different muscle groups, for example rotating the working positions from standing to sitting and vice versa can be an effective strategy [23], since those dentists who were working only in the sitting or standing positions had more LBP than those with rotating standing and sitting positions [24].

\section{Conclusion}

Despite the lack of correlation between LBP intensity and LBPDI with LL, male sex, work experience and BMI were identified as important occupational or individual factors associated with LBP and LBPDI in dentists. Thus, paying attention to ergonomic issues in dentist's workplace such as use of ergonomic equipment and rest schedules, especially with respect to increase of work experience as well as male sex, and furthermore balanceof the BMI by means of diet and physical exercise should be taken into consideration. The small sample size and the study conduction in one dentistry clinic were the limitations of this study; therefore, it is better to conduct similar studies in larger and different populations.

\section{Ethical approval}

All procedures performed in studies involving human participants were in accordance with the ethical student research committee of Shahid Beheshti University of Medical Sciences, Tehran, Iran and with the principles of the declaration of Helsinki (1964) and its later amendments or comparable ethical standards.

\section{Conflict of interest}

The authors declare that there are no conflicts of interests regarding the publication of this article.

\section{Acknowledgments}

This study was related to the project NO. 1396/50176 from Student Research Committee, Shahid Beheshti University of Medical Sciences, Tehran, Iran. We appreciate the "Student Research Committee" and "Research \& Technology Chancellor" in Shahid Beheshti University of Medical Sciences for their financial support of this study.

\section{References}

1. Gupta A, Bhat M, Bansal N, Gupta G. Ergonomics in dentistry. International. Int J Clin Pediatr Dent 2014; 7(1): 30-34. https://doi.org/10.5005/jp-journals-10005-1229.

2. Nadri H, Nadri A, Rohani B, Fasih Ramandi F, Amin Sobhani M, Naseh I. Assessment of Musculoskeletal Disorders Prevalence and Body Discomfort among Dentists by Visual Analog Discomfort Scale. Journal of Mashhad Dental School 2015; 39(4): 363-372. http://eprints.mums.ac.ir/id/eprint/1779.

3. Murphy DC. Ergonomics and dentistry. N Y State Dent J 1997; 63(7) 30-34. https://www.ncbi.nlm.nih.gov/pubmed/9297958

4. De Sio S, Traversini V, Rinaldo F, Colasanti V, Buomprisco G, Perri R, et al. Ergonomic risk and preventive measures of musculoskeletal disorders in the dentistry environment: an umbrella review. PeerJ 2018; 6: e4154. https://doi.org/10.7717/peerj.4154. 
5. Sorensen CJ, Norton BJ, Callaghan JP, Hwang CT, Van Dillen LR. Is lumbar lordosis related to low back pain development during prolonged standing? Man Ther 2015; 20(4): 553-557. https://doi.org/10.1016/j.math.2015.01.001.

6. Chun SW, Lim CY, Kim K, Hwang J, Chung SG. The relationships between low back pain and lumbar lordosis: a systematic review and meta-analysis. Spine J 2017; 17(8): 1180-1191. https://doi.org/10.1016/j.spinee.2017.04.034.

7. Jackowski D, Guyatt G. A Guide to Health Measurement. Clin Orthop Relat Res 2003; (413): 80-89. https://doi.org/10.1097/01.blo.0000079771.06654.13.

8. Bombardier C. Outcome assessments in the evaluation of treatment of spinal disorders: summary and general recommendations. Spine (Phila $\mathrm{Pa}$ 1976) 2000; 3100-3103. https://www.ncbi.nlm.nih.gov/pubmed/11124724.

9. Fairbank JC, Pynsent PB. The Oswestry disability index. Spine (Phila Pa 1976) 2000; 25(22): 2940-2952. https://www.ncbi.nlm.nih.gov/pubmed/11074683.

10. Youdas JW, Garrett TR, Harmsen S, Suman VJ, Carey JR. Lumbar lordosis and pelvic inclination of asymptomatic adults. Phys Ther 1996; 76(10): 1066-1081. https://doi.org/10.1093/ptj/76.10.1066.

11. Clinical Guidelines on the Identification, Evaluation, and Treatment of Overweight and Obesity in Adults - The Evidence Report. National Institutes of Health. Obes Res 1998; 6 Suppl 2: 51S-209S. https://www.ncbi.nlm.nih.gov/pubmed/9813653.

12. Karwowski W, Marras W. Body discomfort assessment tools. In: Occupational ergonomics: engineering and administrative controls. New York: CRC PRES, 1-26. https://www.crcpress.com/Occupational-Ergonomics-Engineeringand-Administrative-Controls/KarwowskiMarras/p/book/9780849318009.

13. Youdas JW, Hollman JH, Krause DA. The effects of gender, age, and body mass index on standing lumbar curvature in persons without current low back pain. Physiother Theory Pract 2006; 22(5): 229-237. https://doi.org/10.1080/09593980600927864.

14. Youdas JW, Suman VJ, Garrett TR. Reliability of measurements of lumbar spine sagittal mobility obtained with the flexible curve. J Orthop Sports Phys Ther 1995; 21(1): 13-20. https://doi.org/10.2519/jospt.1995.21.1.13.

15. Hoppenfeld S. Chapter 9: Physical examination of the lumbar spine. In: Physical examination of the spine \& extremities. New York, 1976: 237263.

https://www.academia.edu/29812814/Physical_Examination_Of_The Spine and Extremities

16. Evcik $D$, Yücel $A$. Lumbar lordosis in acute and chronic low back pain patients. Rheumatol Int 2003; 23(4): 163-165. https://doi.org/10.1007/s00296-002-0268-x.

17. Laird RA, Gilbert J, Kent $\mathrm{P}$, Keating JL. Comparing lumbo-pelvic kinematics in people with and without back pain: a systematic review and meta-analysis. BMC Musculoskelet Disord 2014; 15: 229. https://doi.org/10.1186/1471-2474-15-229.

18. Nadri H, Fasih Ramandi F. Low back and neck pain intensity and relationship with disability index among dentists. JOHE 2017; 5(4): 218-225. http://johe.rums.ac.ir/article-1-225-en.html.

19. Ilyas M, Dharmaji TP. Low Back Pain in dentists of Indonesia. Pakistan Oral \& Dental Journal 2012; 32(3): 464-468. https://pdfs.semanticscholar.org/ec34/3102776756a628473a09d070c a0b9038ba27.pdf.

20. Youdas JW, Garrett TR, Egan KS, Therneau TM. Lumbar lordosis and pelvic inclination in adults with chronic low back pain. Phys Ther 2000; 80(3): 261-275. https://doi.org/10.1093/ptj/80.3.261.

21. Nield-Gehrig JS. Fundamentals of periodontal instrumentation \& advanced root instrumentation. Lippincott Williams \& Wilkins, 2013; 752 p. https://www.academia.edu/36609596/Fundamentals of_Periodontal_Inst rumentation.pdf
22. Nelson-Wong E, Callaghan JP. Transient low back pain development during standing predicts future clinical low back pain in previously asymptomatic individuals. Spine (Phila Pa 1976) 2014; 39(6): E379-383. https://doi.org/10.1097/BRS.0000000000000191.

23. Callaghan JP, McGILL SM. Low back joint loading and kinematics during standing and unsupported sitting. Ergonomics 2001; 44(3): 280-294. https://doi.org/10.1080/00140130118276.

24. Ratzon NZ, Yaros T, Mizlik A, Kanner T. Musculoskeletal symptoms among dentists in relation to work posture. Work 2000; 15(3): 153158. https://www.ncbi.nlm.nih.gov/pubmed/12441484.

\section{Authors:}

Fatemeh Fasih-Ramandi - MSc Student of Occupational Health Engineering, Student Research Committee, Shahid Beheshti University of Medical Sciences, Tehran, Iran. https://orcid.org/0000-0001-5003-7846

Amir Nadri - PhD, Department of Physical Education and Sport Scineces, Izeh Islamic Azad University, Khozestan, Iran. https://orcid.org/0000-00028077-2566.

Gholamheidar Teimori - MSc of Occupational Health, Department of Environmental Health, School of Health, Torbat Heydariyeh University of Medical Sciences, Torbat Heydariyeh, Iran; Health Sciences Research Center, School of Health, Torbat Heydariyeh University of Medical Sciences, Torbat Heydariyeh, Iran. https://orcid.org/0000-0003-4908-4324. Hamed Nadri - PhD Student of Occupational Health Engineering, Department of Occupational Health, School of Medical Sciences, Tarbiat Modares University, Tehran, Iran. https://orcid.org/0000-0002-5221-7098. 